\title{
The Efficacy of a Formula Food for Preventing Postoperative Recurrence in a Tumor Dormancy Model
}

\author{
Jie Zhang ${ }^{\text {l\#}}$, Zhe Wen Chen ${ }^{2 \sharp}$, Ming Yong Miao ${ }^{3}$, Han Ping $\mathrm{Shi}^{4}$ \\ ${ }^{1}$ Department of Respiratory Diseases, the Affiliated Huai'an Hospital of Xuzhou Medical University, Huai'an 223002, China; ${ }^{2}$ The \\ Second Affiliated Hospital, Wenzhou Medical University, Wenzhou 325000, China; ${ }^{3}$ Department of Biochemistry and Molecular \\ Biology, Naval Military Medical University, Shanghai 200433, China; ${ }^{4}$ Department of Gastrointestinal Surgery / Clinical Nutrition \\ Beijing Shijitan Hospital / Capital Medical University Beijing International Science and Technology Cooperation Base for Cancer \\ Metabolism and Nutrition / Department of Oncology Capital Medical University Beijing 100038 China
}

\begin{abstract}
Objective To establish a lung cancer dormancy mouse model and verify the effects of Wushen (WS), a formula food, on postoperative recurrence. Methods We established a Lewis cell tumor dormancy model system that definitively links surgery and the subsequent wound-healing response to the outgrowth of lung cancer cells. We used this model to observe the effects of WS on the postoperative recurrence and the nutritional status of the mice. Finally, the immunocyte subtypes and cytokine levels in the serum and spleens of mice were detected by flow cytometry and ELISA. Results The recurrence rate in the WS group was obviously lower than that in the control group. Wushen increased the body weights and serum albumin levels of the mice. The levels of $\mathrm{NK}, \mathrm{Gr} 1^{+} \mathrm{CD} 11 \mathrm{~b}^{+} \mathrm{CD} 3^{+} \mathrm{CD} 8^{+}$and $\mathrm{CD}^{+} \mathrm{CD}^{+} \mathrm{T}$ cells in the spleens of mice in the WS group were also increased. Compared with the control group, the levels of $\mathrm{CD}^{+} \mathrm{IFN}-\gamma^{+}, \mathrm{CD} 4^{+} \mathrm{IL}-2$ and $\mathrm{CD} 4^{+} / \mathrm{IL}-10^{+}$in the spleens of mice in the WS group were decreased. Wushen also seemed to decrease the levels of IL- 6 and TNF- $\alpha$, but the decrease was not significant. Conclusion The postoperative lung cancer recurrence model was successfully established. Wushen inhibited postoperative recurrence, apparently by regulating the level of immune cell subtypes and cytokines in the serum and spleen.
\end{abstract}

Key words: Wushen; Immune regulation; Tumor dormancy; Postoperative recurrence

\section{Introduction}

Primary bronchogenic lung cancer originates from the bronchial mucosa or glands. Lung cancer has the highest cancer-related morbidity and mortality rates worldwide [1]. Due to increased awareness and routine physical examinations, the detection rate of early lung cancer has greatly increased, providing the opportunity to use radical surgery for lung cancer. However, even for an R0 (marginnegative) resection, the postoperative recurrence rate is as high as $45.4 \%$, with local recurrence observed in $19 \%$ of stage IA patients and a 5-year postoperative survival rate of $60 \% \sim 70 \%$ in stage I patients [2-4]. It has traditionally been believed that the main reasons for the high rates of recurrence and metastasis are the relatively late diagnosis of the disease and the high incidence of micrometastasis even at early stages [5-6]. Recently, cancer dormancy was found to play an important role in the outgrowth of cancer cells following tumor resection. Cancer dormancy

\#Jie Zhang and Zhe Wen Chen contributed equally to this work. Corresponding authors: Han Ping Shi, MD, PhD, FACS, Department of Gastrointestinal Surgery / Clinical Nutrition, Beijing Shijitan Hospital, Capital Medical University, Beijing 100038, China; Tel: +86 106392 6985; Fax: +86 106392 6385; Email: shihp@ccmu.edu.cn; Ming Yong Miao, MD, PhD, Department of Hepatobiliary Surgery, the Second Afliated Hospital of Wenzhou Medical University, Wenzhou, Zhejiang 325000, China; Tel: +86 218198 0970; Fax: +86 218198 0970; Email: miaomy@163.com is a stage in cancer progression where the cells cease dividing but survive in a quiescent (G0/G1) state while waiting for appropriate environmental conditions to begin proliferating again [7]. Dormant cancer cells are thought to be present early in tumor progression, in micrometastases, or in cells left behind in minimal residual disease (MRD) after what was thought to be a successful treatment of the primary tumor. Krall JA et al. [8] raised the possibility that post-surgical inflammation may lead to the appropriate conditions for cancer proliferation. Therefore, the establishment of an appropriate tumor dormancy model to study the mechanism (s) underlying tumor dormancy and proliferation in vivo would facilitate the identification of drugs that would maintain dormancy or inhibit the proliferation of dormant cells. A few efforts have already been made in these areas [9-11], but an ideal model has not yet been developed.

Medicine food homology (MFH), a basic concept in Traditional Chinese Medicine (TCM), emphasizes that TCM and foods are from the same source $[12,13]$. Chinese people prefer food over drugs for health care [14]. The viewpoint of MFH also conforms to the present dietary preference for a "green healthy life" [15]. People worldwide are paying increasing attention to the health benefits of a varied, nutritious, and balanced diet. In China, a new health food, termed "Wushen", was developed as a rich source of anti-inflammatory and immunoregulatory components. 
Wushen is produced from 55 different ingredients, including meat, cereals, vegetables, and plants. In our previous study, we demonstrated that Wushen has antitumor effects using an S180 tumor-bearing mouse model [16].

In this manuscript, we describe the establishment of a mouse tumor dormancy model that simulates the surgical and postoperative status of patients with lung cancer and the subsequent tumor recurrence and metastasis. The efficacy of Wushen for preventing postoperative recurrence was examined using this tumor dormancy model.

\section{Materials and Methods}

\section{Establishment of the model of lung cancer dormancy}

All experimentation on animals was approved by the Institutional Animal Care and Use Committee of Naval Military Medical University. For tumor implantation, C57 mice (male, aged 4 weeks, CAVENS, Changzhou, China) were housed in a specific pathogen-free facility. One week later, a suspension of $2 \times 10^{6}$ Lewis cells in $200 \mu \mathrm{l}$ PBS was inoculated subcutaneously into the right dorsal branch of the mouse. Two weeks later, the transplanted tumor diameter was measured with Vernier calipers, and the tumor volume was estimated according to the equation $\mathrm{V}=\mathrm{ab}{ }^{2} \pi / 6$ (where $\mathrm{a}$ is the maximum diameter, and $\mathrm{b}$ is the minimum diameter). Surgery was then performed to remove the tumor. The incision was sutured with silk thread. Mice with no visible tumor at the site of the inoculation (simulating a complete resection) were kept for four weeks after surgery.

The model was considered successful, with no residual tumors in the mice after surgery. Nine mice were allocated to each of four groups. The groups were as follows: a control group fed with a standard diet (SD); an experimental group that received simple trauma (Model); an experimental group that received a simple trauma and feeding with WS; and a group that received simple trauma group and a positive control drug (PCD), penicillin G sodium salt [17] by intraperitoneal injection at $20,000 \mu \mathrm{m}$ /day. The simple trauma comprised a small incision and the removal of $3 \mathrm{~mm}$ of the tail. The compositions of the Wushen and standard diet are shown in Table 1. To control for the injectionrelated trauma, the non-PCD groups were injected with an equal volume of normal saline.

Table 1 The exact composition of the diets.

\begin{tabular}{lcc}
\hline & Standard diet (/100g) & Wushen (/100g) \\
\hline Protein & 19.2 & 22.1 \\
Fat & 4.1 & 12.7 \\
Carbohydrate & 50.4 & 36.4 \\
Fiber & 9.6 & 21.7 \\
Ash content & 8.2 & 3.6 \\
Water content & 8.5 & 3.5 \\
Calories & $312 \mathrm{kcal}$ & $391 \mathrm{kcal}$ \\
\hline
\end{tabular}

\section{Sample acquisition and detection of basic indices}

To obtain serum, blood was collected from the supraorbital vein of each mouse and placed in a heparincontaining tube at $4^{\circ} \mathrm{C}$. The blood was then centrifuged at 4,000 rpm for $10 \mathrm{~min}$, and the serum obtained was saved for analysis. The concentration of albumin (ALB) in the mouse serum was detected with an ALB enzyme-linked immunosorbent assay (ELISA) kit (Nanjing Jiancheng Bioengineering Institute, Nanjing, China). For tissue sample preparation, mice were sacrificed and immediately anatomized on ice to obtain the spleen and hind limbs. The weights of the spleens were recorded. The Parameter index $(\mathrm{mg} / \mathrm{g})$ was calculated as: spleen weight $(\mathrm{mg}) /$ body weight (g). The muscle circumference of the mouse hind limbs was measured and recorded.

\section{Indices of immunologic function}

Mouse spleen tissues were collected to detect immune cell subsets. Briefly, single cell suspensions were prepared from fresh spleen tissues using the trituration method, and the cell density was adjusted to $1 \times 10^{6}$ cells $/ \mathrm{ml}$. Red blood cells (RBCs) were lysed with an RBC lysis buffer (Cat. No. 420301; Biolegend, San Diego, CA, USA) and the cells were labeled with antibodies. Flow cytometry was used to measure the percentages of different immune cell subsets. The antibodies used were as follows: CD3 phycoerythrin (PE)-cy7 (Cat. No. 552774; BD Biosciences, San Jose, CA, USA), CD8 allophycocyanin (APC)-cy7 (Cat. No. 557654; BD Biosciences), NK1.1 APC (Cat. No. 561117; BD Biosciences), Alexa Fluor 488 rat anti-mouse Foxp3 (Cat. No. 560403; BD Biosciences), IL-10 BV605 (Cat. No. 564082; BD Biosciences), Ly6G fluorescein isothiocyanate (FITC; Cat. No. 551460; BD Biosciences), and CD4 PE (Cat. No. 100407; Biolegend).

\section{Statistical analysis}

SPSS 22.0 and GraphPad Prism 7.0 were used for the statistical analyses. All data were analyzed by a oneway analysis of variance followed by the least significant difference multiple comparison post-hoc test, if appropriate. The significance level was set to $\alpha=0.05(P<0.05)$.

\section{Results \\ Tumor recurrence}

Tumor growth was observed (unmagnified view) in 8 of 44 mice within two weeks after palliative surgery, and no tumor growth was observed from week 2 to week 4, suggesting that the postsurgical lung cancer recurrence model was successfully established in these 36 mice. These mice were randomized to the different groups, and then examined for visible (to the naked eye) tumors at 6 weeks postoperatively. The rates of tumor recurrence in the various groups were $22.22 \%$ (2/9 mice) in the SD group, $66.66 \%$ (6/9) in the Model group, 33.33\% (3/9) in the WS group, and $33.33 \%(3 / 9)$ in the PCD group (Figure 1). These 
findings suggested that the traumatic stimulus increases the risk of postoperative recurrence, and that Wushen may decrease the impact of this trauma.

\section{General condition of the mice}

At 6 weeks postoperatively, the weights of the mice in the Model group was the lowest, while that of the WS group was higher than that of the Model group and the PCD group, as shown in Figure 2A. At the end of the experiment, the serum albumin level of the mice in the WS group was significantly higher than the SD group (Figure 2B). However, there was no significant difference in the muscle circumference of the hind limbs among the groups (Figure 2C). These findings indicated that WS could improve the general nutritional status of mice and may prevent weight loss.
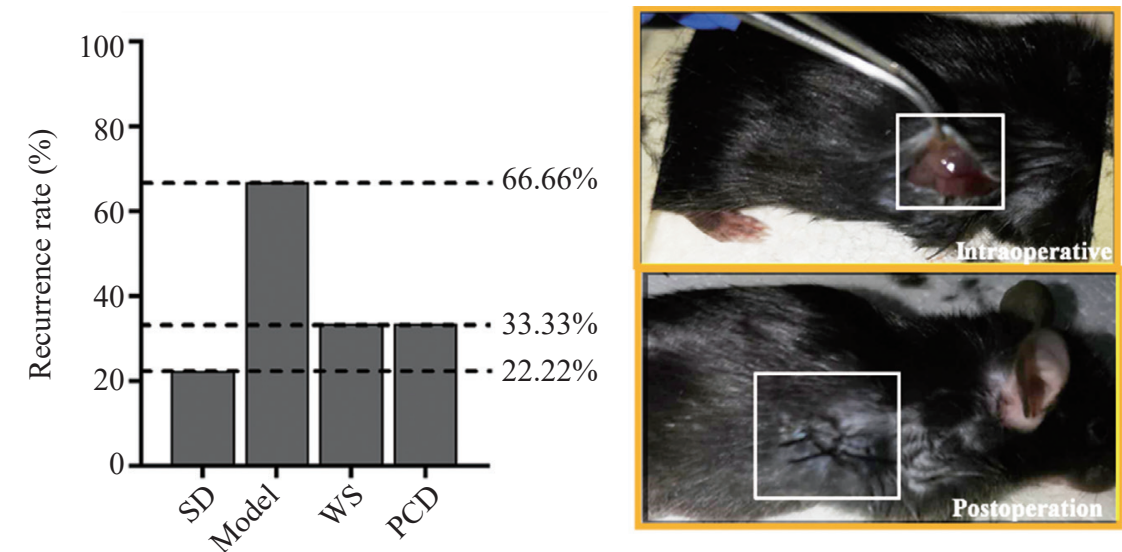

Figure 1 The tumor recurrence rates in different groups

A

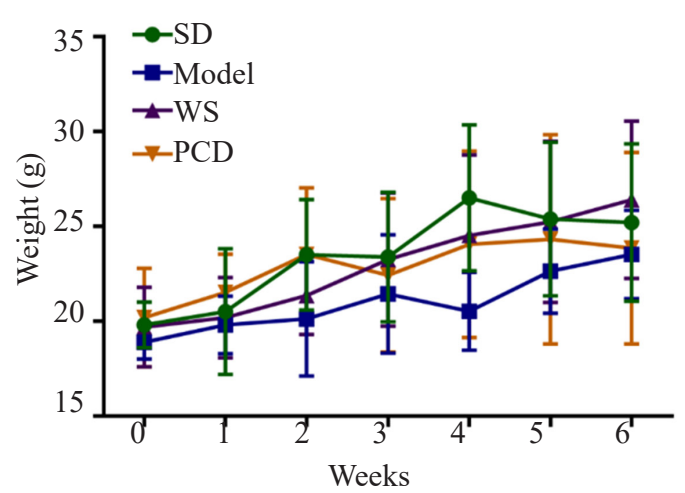

B

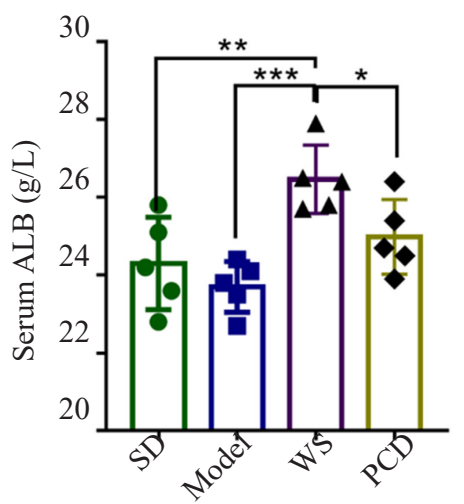

C

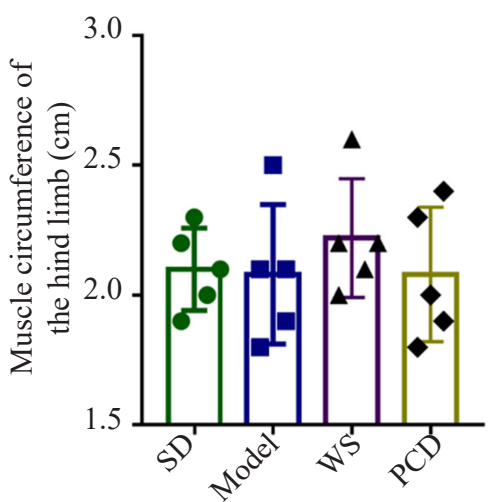

Figure 2 A comparison of the general condition of the mice. (A) The weight of mice in the different groups. The serum ALB level (B) and muscle circumference of the hind limb $(\mathrm{C})$ of mice in the different groups (Values are indicated as mean $\pm \mathrm{SD}, * P<0.05, * * P<0.01$ and $* * * P<0.001)$.
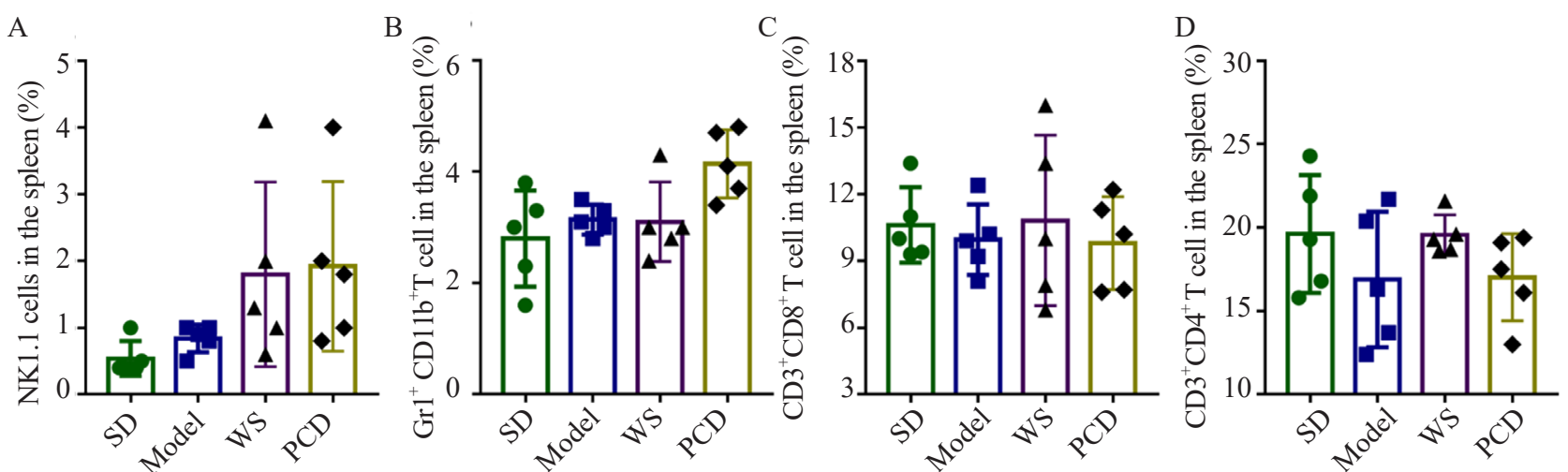

Figure 3 The levels of different immune cell subtypes in the spleen. The levels of NK1.1 (A), Gr1 $1^{+} \mathrm{CD} 11 \mathrm{~b}^{+}(\mathrm{B}), \mathrm{CD} 3^{+} \mathrm{CD} 8^{+}(\mathrm{C})$ and $\mathrm{CD}^{+} \mathrm{CD}^{+}$(D) $\mathrm{T}$ cells in the spleens of mice in the different groups (Values are indicated as mean $\pm \mathrm{SD}$ ). 


\section{Immune cell subtype levels in the spleen}

We detected the levels of several immune cell subtypes in the spleen. Compared with the Model group, the levels of $\mathrm{NK}, \mathrm{Gr}^{+} \mathrm{CD} 1 \mathrm{~b}^{+} \mathrm{CD}^{+} \mathrm{CD}^{+}$and $\mathrm{CD}^{+} \mathrm{CD}^{+} \mathrm{T}$ cells in the spleens of mice in the WS group were increased, but the differences were not statistically significant (Figure 3).

\section{The proportion of effector cells in the spleen}

Compared with the control (SD) group, the spleen $\mathrm{CD}^{+}{ }^{\text {Perforin }}{ }^{+}, \mathrm{CD}^{+} \mathrm{IFN}^{-} \gamma^{+}, \mathrm{CD} 4^{+} / \mathrm{IL}-4^{+}, \mathrm{CD} 4^{+} / \mathrm{IL}-2^{+}$and $\mathrm{CD}^{+} / \mathrm{IL}-10^{+}$cells in the Model group were increased. The levels of $\mathrm{CD}^{+} \mathrm{IFN}^{-} \gamma^{+}, \mathrm{CD} 4^{+} \mathrm{IL}-2$ and $\mathrm{CD} 4^{+} / \mathrm{IL}-10^{+}$in the spleens of mice in the WS group were decreased compared to the Model group, but the differences were not statistically significant due to the high variation among mice (Figure 4).

\section{Relevant cytokine levels in the serum}

Compared with the SD group, the serum IL-6 and TNF- $\alpha$ levels in the Model group were increased. WS seemed to decrease the levels of IL-6 and TNF- $\alpha$ (Figure 5), but the difference was also not significant.

\section{Discussion}

Wushen is a health food comprising 55 different natural ingredients. In our previous study, we demonstrated that Wushen has antitumor effects using an S180 tumorbearing mouse model [17]. Some of the components of Wushen, including $\beta$-carotene, melatonin, lutein, choline, procyanidin, spinacene, anthocyanin, and zeaxanthine, were previously reported to exert antioxidant and immuneenhancing effects (supplementary Table 1 and 2). For instance, $\beta$-carotene can promote immune responses through the activation of splenocytes and macrophages [18]. Melatonin modulates a wide range of physiological functions with pleiotropic effects on the immune system. A large amount of research studies has shown that melatonin is an immune buffer, acting as a stimulant under basal or immunosuppressive conditions, or as an anti-inflammatory compound in the presence of exacerbated immune responses, such as acute inflammation [19]. Peiffer DS et al. found that dietary consumption of anthocyanin constituents alters innate immune cell trafficking in esophageal cancer [20]. Lutein, choline, procyanidin, spinacene and zeaxanthine can also stimulate immune responses, and may be partly responsible for the reduction in recurrence. Additionally, compared with the standard diet, this formula food provides energy, high-quality protein and balanced nutrition, which would be expected to improve the nutritional status, as was
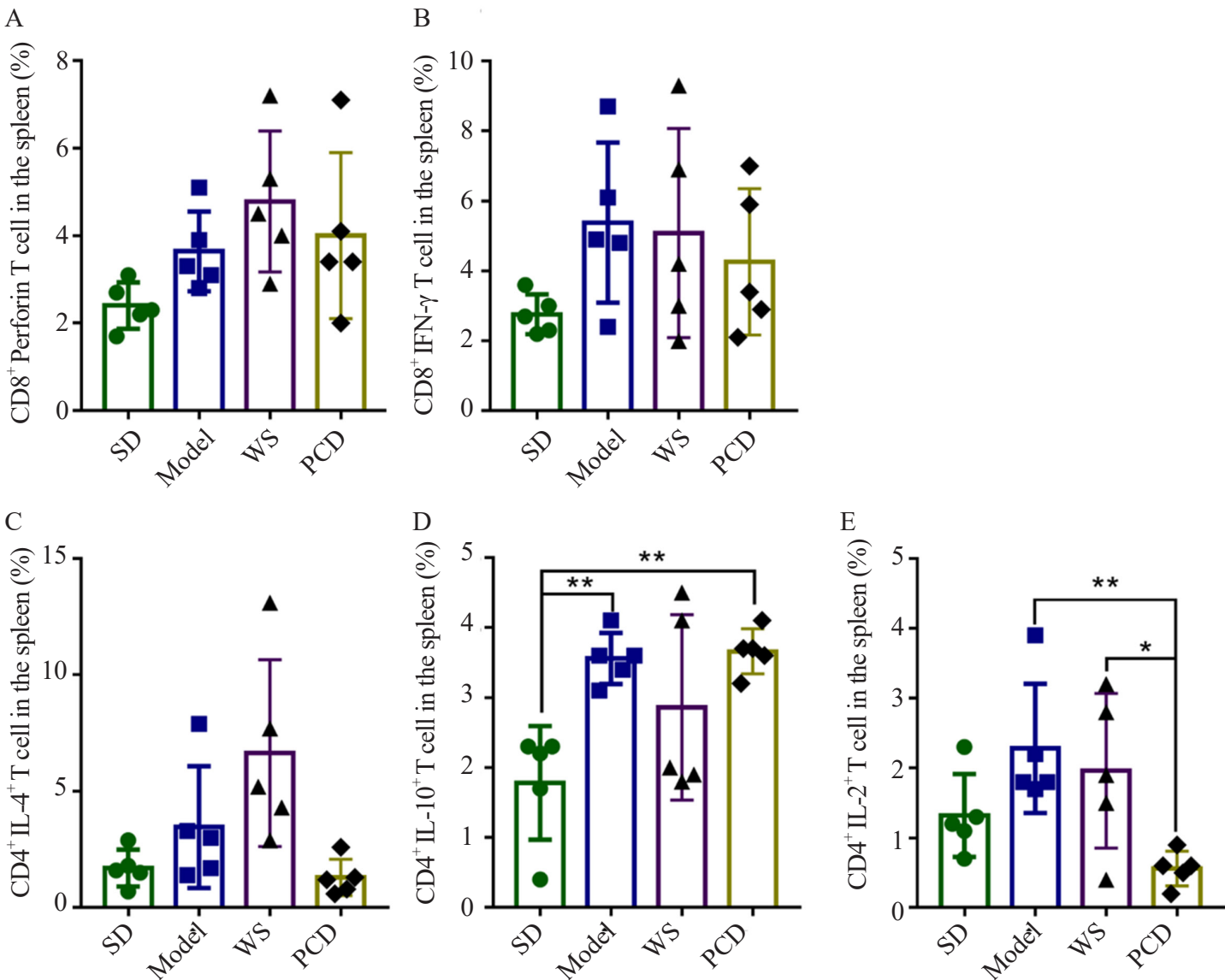

Figure 4 The proportions of effector cells in the spleen. The spleen CD8 ${ }^{+}$Performin ${ }^{+}(\mathrm{A}), \mathrm{CD} 8^{+} \mathrm{IFN}-\gamma^{+}$(B), CD4 ${ }^{+} / \mathrm{IL}_{-} 4^{+}$ (C), $\mathrm{CD}^{+} / \mathrm{IL}-2^{+}$(D) and $\mathrm{CD}^{+} / \mathrm{IL}-10^{+}$(E) levels in the different groups (Values are indicated as mean $\pm \mathrm{SD}, * P<0.05,{ }^{* *} P$ $<0.01)$. 
suggested by the higher serum albumin level.

Although there have been major advances in the treatment of various cancers, postoperative recurrence and metastasis remain a problem [21-23]. There is evidence that even after surgery, dormant tumor cells can remain in the body for a long time [24]. Upon stimulation by certain factors, the tumor cells escape from immune surveillance, break the dormant state, and are reactivated to undergo proliferation and form metastasis [25-26]. This topic has been attracting increasing interest in recent years because the identification of the mechanisms by which tumor cells become dormant and are subsequently reactive would provide targets to prevent the immune escape and metastasis of dormant cells.

Therefore, the establishment of a good animal model of tumor dormancy, which reflects the tumor microenvironment, is important to study of the mechanism(s) underlying dormancy and reactivation. In this study, a postoperative lung cancer recurrence model was established by simulating the postoperative state and a subsequent trauma to induce an inflammatory state. Although the number of animals was small and further studies will be needed to confirm the findings, our results suggest that Wushen can significantly reduce the development of postoperative lung cancer recurrence, likely due to improved immune function and a reduction in inflammatory factors. These findings are in agreement with the fact that Wushen and its various constituents have already been demonstrated to have immunoregulatory and anti-inflammatory effects.

NK cells play an important role in anti-tumor immunity. As the main effector cells of the innate immune system, NK cells have a wide range of biological functions. Together with cytotoxic T lymphocytes, NK cells are responsible for the first and second lines of defense against both malignant cells and microbial infections [27,28]. The anti-tumor immunity of the human body is dominated by cellular immunity, which is completed by $\mathrm{CD} 4^{+}$and $\mathrm{CD} 8^{+}$ cells. $\mathrm{CD}^{+}$cells can promote the anti-tumor effects of effector cells, while $\mathrm{CD} 8^{+}$cells mainly play the opposite role to induce immunosuppression [29]. Initially $\mathrm{CD}^{+}$ and $\mathrm{CD} 8^{+} \mathrm{T}$ cells can be transformed into different $\mathrm{Th}$ subtypes, depending on the cytokine signals present in the tissue microenvironment. Therefore, disorders affecting cytokine signaling may lead to imbalances in the various $\mathrm{T}$ cell subsets, leading to the occurrence and development of diseases [30]. In the present study, we found that the $\mathrm{CD}^{+}$Perforin $^{+}, \mathrm{CD} 8^{+} \mathrm{IFN}_{-} \gamma^{+}, \mathrm{CD} 4^{+} / \mathrm{IL}-4^{+}, \mathrm{CD} 4^{+} / \mathrm{IL}^{-} 2^{+}$ and $\mathrm{CD} 4^{+} / \mathrm{IL}-10^{+}$cell levels in the Model group were all increased. Wushen could regulate the expression levels of at least some of these, which may underlie its ability to decrease the postoperative recurrence rate.

Most of the previous studies related to tumor dormancy used surgery that involved the removal of primary tumors. Therefore, in addition to triggering a systemic postsurgical wound-healing response, such excision also leads to the loss of tumor-derived systemic factors. The loss of these tumorspecific factors was cited as the primary explanation for the results. This made it difficult to draw conclusions about the impact of surgery on the outgrowth of distant tumors. Krall JA et al. [8] established a reliable model which avoided the resection of a large primary tumor while still faithfully mimicking the tissue damage and inflammation associated with surgical tumor resection. Their model ensured that the extent of wounding was highly consistent across large numbers of mice. Their experiments provide strong evidence of the systemic effects of surgery on deposits of immunogenic tumor cells. Our present study also found that a formula food (WS) could reduce postoperative recurrence in a mouse model of tumor dormancy. However, this study was small, with relatively high variation among animals, so further research is needed to confirm the findings and elucidate the detailed effects of WS on postoperative recurrence.
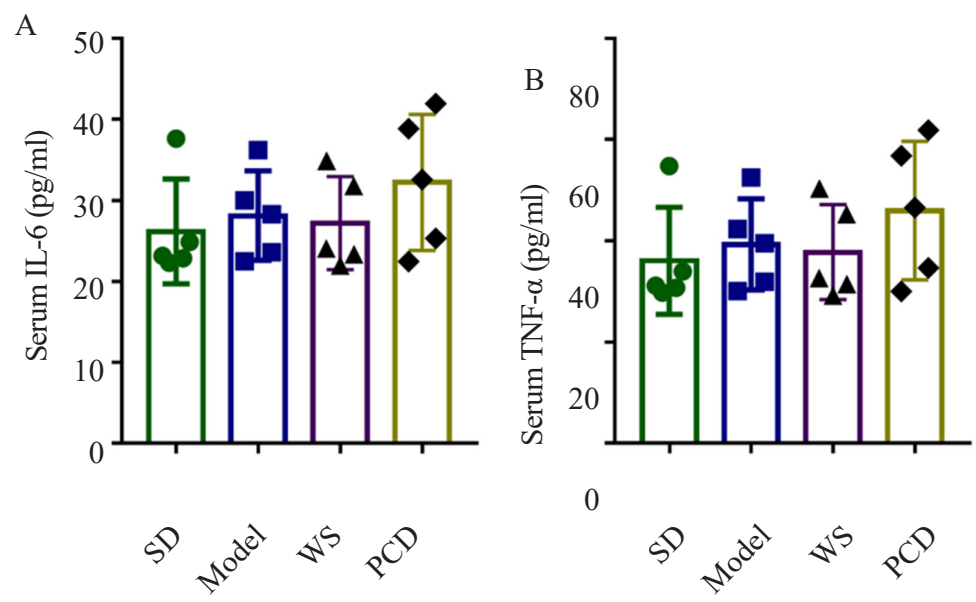

Figure 5 The levels of cytokines in serum. The levels of serum IL-6 (A) and $\mathrm{TNF}-\alpha(\mathrm{B})$ in the different groups (Values are indicated as mean $\pm \mathrm{SD}$ ). 


\section{Conclusion}

We herein established a postoperative recurrence model of Lewis lung cancer. Wushen exhibited promising effects against postoperative recurrence, likely due to it regulating the level of immune cell subtypes and cytokines in the serum and spleen. In addition, WS could increase the body weight and serum albumin level of mice. These findings warrant further exploration of the anti-cancer effects of WS, particularly for the prevention of postoperative recurrence.

\section{Conflict of Interests}

Han Ping Shi's lab received grant support from Yantai Wushen Biotechnology Co. LTD.

\section{References}

1. Siegel RL, Miller KD, Jemal A. Cancer statistics, 2018. Ca A Cancer J Clin 2018;60(5):277-300.

2. Haruki T, Miwa K, Araki K, Taniguchi Y, Nakamura H. Distribution and prevalence of locoregional recurrence after video-assisted thoracoscopic surgery for primary lung cancer. Thorac Cardiovasc Surg 2016;64(6):526-32.

3. Sekihara K, Hishida T, Yoshida J, Oki T, Omori T, Katsumata S, Ueda T, Miyoshi T, Goto M, Nakasone S, Ichikawa T, Matsuzawa R, Aokage K, Goto K, Tsuboi M. Long-term survival outcome after postoperative recurrence of non-small-cell lung cancer: who is “cured" from postoperative recurrence? Eur J Cardiothorac Surg 2017; 52(3):522-8.

4. Bando T, Onishi C, Imai Y. Treatment-associated symptoms and coping of postoperative patients with lung cancer in Japan: development of a model of factors influencing hope. Japan J Nurs Sci 2017;15(3):237-48.

5. Niwa H, Masaoka A. Surgical therapy for local recurrence and distant metastasis of lung cancer. Kyobu Geka 1995;48(1):8-12.

6. Yan X, Jiao SC, Zhang GQ, Guan Y, Wang JL. Tumor-associated immune factors are associated with recurrence and metastasis in nonsmall cell lung cancer. Cancer Gene Ther 2017;24(2):57-63.

7. Liu Y, Lv J, Liu J, Liang X, Jin X, Xie J, Zhang L, Chen D, Fiskesund R, Tang K, Ma J, Zhang H, Dong W. STAT3/p53 pathway activation disrupts IFN- $\beta$-induced dormancy in tumor-repopulating cells. J Clin Invest 2018;128(3):1057-73.

8. Krall JA, Reinhardt F, Mercury OA, Pattabiraman DR, Brooks MW, Dougan M, Lambert AW, Bierie B, Ploegh HL, Dougan SK, Weinberg RA. The systemic response to surgery triggers the outgrowth of distant immune-controlled tumors in mouse models of dormancy. Sci Trans Med 2018;10(436):eaan3464.

9. Zhou Y, Liu Q, Dai X, Yan Y, Yang Y, Li H, Zhou X, Gao W, Li X, $\mathrm{Xi} Z$. Transdifferentiation of type II alveolar epithelial cells induces reactivation of dormant tumor cells by enhancing TGF- $\beta 1 /$ SNAI2 signaling. Oncol Rep 2018;39(4):1874-82.

10. Benlloch S, Galbis-Caravajal JM, Alenda C, Peiró FM, SanchezRonco M, Rodríguez-Paniagua JM, Baschwitz B, Rojas E, Massutí B. Expression of molecular markers in mediastinal nodes from resected stage I non-small-cell lung cancer (NSCLC): prognostic impact and potential role as markers of occult micrometastases. Ann Oncol 2009;20(1):91-7.
11. Endo H, Okami J, Okuyama H, Nishizawa Y, Imamura F, Inoue M. The induction of MIG6 under hypoxic conditions is critical for dormancy in primary cultured lung cancer cells with activating EGFR mutations. Oncogene 2017;36(20):2824-34.

12. Liu DY, Li YH, Xu YT, Zhu Y. Anti-aging traditional Chinese medicine: potential mechanisms involving AMPK pathway and calorie restriction based on "medicine-food homology" theory. Zhongguo Zhong Yao Za Zhi 2016;41:1144-51.

13. Song DX, Jiang JG. Hypolipidemic Components from medicine food homology species used in China: Pharmacological and health effects. Arch Med Res 2017;48(7):569-81.

14. Luo J, Xu H, Chen KJ. Potential benefits of Chinese herbal medicine for elderly patients with cardiovascular diseases. J Geriatr Cardiol 2013;10(4):305.

15. Hou Y, Jiang JG. Origin and concept of medicine food homology and its application in modern functional foods. Food Funct 2013;4:1727-41.

16. Wang $C$, Peng $R$, Wang L, Chen $P$, Wang S, Xu X, Zhang Q, Lin S, Hu X. Wushen, a food mixture containing 55 different natural ingredients, inhibits S180 tumor growth in vivo. Food Funct 2015;5(7):1475-80.

17. Campbell PC. Large doses of penicillin in the prevention of surgical wound infection. Lancet 1965;2(7417):805-10.

18. Kim HY, Nam SY, Yang SY, Kim HM, Jeong HJ. Cucurbita moschata Duch. and its active component, $\beta$-carotene effectively promote the immune responses through the activation of splenocytes and macrophages. Immunopharmacol Immunotoxicol 2016;38(5):21926.

19. Carrillo-Vico A, Lardone PJ, Alvarez-Sánchez N, RodríguezRodríguez A, Guerrero JM. Melatonin: Buffering the immune system. Int J Mol Sci, 2013;14(4):8638-83.

20. Peiffer DS, Wang LS, Zimmerman NP, Ransom BW, Carmella SG, Kuo CT, Chen JH, Oshima K, Huang YW, Hecht SS, Stoner GD. Dietary consumption of black raspberries or their anthocyanin constituents alters innate immune cell trafficking in esophageal cancer. Cancer Immunol Res 2016;4(1):72-82.

21. Kishi S, Minato M, Saijo A, Murakami N, Tamaki M, Matsuura M, Murakami T, Nagai K, Abe H, Nishioka Y, Doi T. IgA nephropathy after nivolumab therapy for postoperative recurrence of lung squamous cell carcinoma. Intern Med 2018;57(9):1259-63.

22. Kanou T, Okami J, Tokunaga T, Ishida D, Kuno H, Higashiyama M. Prognostic factors in patients with postoperative brain recurrence from completely resected non-small cell lung cancer. Thorac Cancer 2015;6(1):38-42.

23. Yamaguchi Y. [Strategy and treatment of postoperative recurrence of primary lung cancer]. Gan to Kagaku Ryoho 1983;10(11):2258-67.

24. Preciado JA, Reátegui E, Azarin SM, Lou E, Aksan A. Immobilization platform to induce quiescence in dormancy-capable cancer cells. Technology 2017;05(03):129-38.

25. Peppicelli S, Andreucci E, Ruzzolini J, Laurenzana A, Margheri F, Fibbi G, Del Rosso M, Bianchini F, Calorini L. The acidic microenvironment as a possible niche of dormant tumor cells. Cell Mol Life Sci 2017;74(15):2761-71.

26. Cackowski FC, Taichman RS. Parallels between hematopoietic stem cell and prostate cancer disseminated tumor cell regulation. Bone 
2018;2019;119:82-6.

27. Lavin Y, Kobayashi S, Leader A, Amir ED, Elefant N, Bigenwald C, Remark R, Sweeney R, Becker CD, Levine JH, Meinhof K, Chow A, Kim-Shulze S, Wolf A, Medaglia C, Li H, Rytlewski JA, Emerson RO, Solovyov A, Greenbaum BD, Sanders C, Vignali M, Beasley MB, Flores R, Gnjatic S, Pe'er D, Rahman A, Amit I, Merad M. Innate immune landscape in early lung adenocarcinoma by paired single-cell analyses. Cell 2017;169(4):750-65.e17.

28. Wang Z, Guo L, Song Y, Zhang Y, Lin D, Hu B, Mei Y, Sandikin D, Liu H. Augmented anti-tumor activity of NK-92 cells expressing chimeric receptors of TGF- $\beta$ R II and NKG2D. Cancer Immunol Immunother 2017;66(4):537-48

29. Song A, Song J, Tang X, Croft M. Cooperation between CD4 and CD8 T cells for anti-tumor activity is enhanced by OX40 signals. Eur J Immunol 2007;37(5):1224-32

30. Thaxton JE, Wallace C, Riesenberg B, Zhang Y, Paulos CM, Beeson CC, Liu B, Li Z. Modulation of endoplasmic reticulum stress controls $\mathrm{CD}^{+} \mathrm{T}$ cell activation and anti-tumor function. Cancer Immunol Res 2017;5(8):666-75 